\title{
V Liraglutide for type 2 diabetes - new data
}

In May this year, we published an article on $\mathbf{\nabla}$ Liraglutide for type 2 diabetes (DTB 2010; 48: 50-3). At the time, there were no published randomised controlled trials comparing liraglutide with $\mathbf{\nabla}$ sitagliptin. However, since then, there has been publication of a 26-week non-blinded randomised trial that compared subcutaneous liraglutide $1.2 \mathrm{mg}$ and $1.8 \mathrm{mg}$ daily with oral sitagliptin $100 \mathrm{mg}$ daily, all in addition to metformin, in 665 patients with type 2 diabetes and inadequate glycaemic control $\left(\mathrm{HbA}_{1 c} 7.5-10.0 \%\right)$ despite treatment with metformin (at least 1,500mg daily) for 3 months or longer.'

At 26 weeks, in this study, the mean change in $\mathrm{HbA}_{1 c}$ levels (the primary outcome measure) from a baseline of around $8.5 \%$ was greater with both doses of liraglutide than with sitagliptin $(1.2 \mathrm{mg}:-1.24 \%, 95 \% \mathrm{Cl}-1.37$ to $-1.11 ; 1.8 \mathrm{mg}:-1.50 \%, 95 \% \mathrm{Cl}-1.63$ to -1.37 ; sitagliptin $-0.90 \%$, $95 \% \mathrm{Cl}-1.03$ to -0.77$)$. In terms of secondary outcome measures, mean weight loss was greater with both doses of liraglutide than with sitagliptin (1.2mg: $-2.86 \mathrm{~kg}, 95 \% \mathrm{Cl}-3.39$ to $-2.32 ; 1.8 \mathrm{mg}:-3.38 \mathrm{~kg}, 95 \% \mathrm{Cl}-3.91$ to -2.84 ; sitagliptin: $-0.96 \mathrm{~kg}, 95 \% \mathrm{Cl}-1.50$ to -0.42 ), but neither drug reduced systolic blood pressure significantly. More patients developed adverse events with liraglutide (66\% with $1.2 \mathrm{mg}$ and $73 \%$ with $1.8 \mathrm{mg}$ ) than with sitagliptin (58\%), the most common being gastrointestinal symptoms, particularly nausea that diminished over time.

The results of this study show that liraglutide reduces $\mathrm{HbA}_{1 c}$ levels more than sitagliptin, but do not affect the conclusion of DTB's review on liraglutide for type 2 diabetes. This stated that "liraglutide is expensive and currently lacks long-term safety data. Therefore, we believe that it should be considered only after conventional oral hypoglycaemic therapy (including a glitazone) has failed, and where the avoidance of weight gain is crucial, insulin therapy is contraindicated, or the individual is unable to tolerate exenatide."

$[R=$ randomised controlled trial; $M=$ meta-analysis $]$

$\mathrm{R}$ 1. Pratley RE et al. Liraglutide versus sitagliptin for patients with type 2 diabetes who did not have adequate glycaemic control with metformin: a 26 -week, randomised, parallel-group, open-label trial. Lancet 2010; 375: 1447-56. 